\title{
The role of corticotropin-releasing hormone receptor 1 in the development of colitis-associated cancer in mouse model
}

\author{
Yunxin Liu, Xianjun Fang, Jie Yuan, Zongxing Sun, Chuanhua Li, Rong Li, \\ Li Li, Chao Zhu, Rong Wan, Rui Guo, Lai Jin and Shengnan Li \\ Key Laboratory of Cardiovascular and Molecular Intervention, Department of Pharmacology, \\ Nanjing Medical University, Nanjing 210029, People's Republic of China
}

Correspondence should be addressed to $\mathrm{S} \mathrm{Li}$

Email

snli@njmu.edu.cn

\begin{abstract}
Patients with ulcerative colitis are at a very high risk of developing colorectal cancer. Corticotrophin-releasing hormone (CRH) family peptides and their receptors (CRHRs) are found to modulate inflammation and tumor cell growth. However, the role of CRH family peptides and their receptors in the inflammation-related colon cancer is still unknown. The aim of this study was to investigate the functions of CRHR1 signaling on the development of colitis-associated cancer (CAC). Crhr1-deficient $\left(\mathrm{Crhr}^{-1-}\right)$ mice were used to explore the role of CRHR1 in the development of azoxymethane (AOM) and dextran sodium sulfate (DSS)induced CAC. WT $\left(\mathrm{Crhr}^{+/+}\right)$littermates were set as control. We found that the expression of CRHR1 and its endogenous ligands: urocortin and $\mathrm{CRH}$ were enhanced in the colon of $\mathrm{Crhr}^{+/+}$mice during treatment with $\mathrm{AOM}$ and DSS. Tumorigenesis was significantly reduced in $\mathrm{Crhr}^{-1-}$ mice, determined by analysis of survival rate (increased by $20 \%$ ), weight loss (decreased by 10\%), tumor formation (decreased by $60 \%$ in tumor number), histological scores (decreased by $58 \%$ ), and cytokine production. During early CAC tumorigenesis, $\mathrm{Crhr}^{-1-}$ mice exhibited much less tumorigenesis, accompanied by lower inflammatory response, including decreased IL1 $\beta$, IL6 and TNF $\alpha$ expression and macrophage infiltration and increased IL10 expression. Moreover, $\mathrm{Crhr}^{-1-}$ mice displayed a reduced activation of NFKB and STAT3 phosphorylation with decreased proliferating and enhanced apoptotic cells in the colon. In conclusion, CRHR1 has a proinflammatory and therefore a protumorigenesis effect in terms of CAC, which may be helpful to develop new therapeutic approaches for inflammation and cancer prevention and treatment.
\end{abstract}

\section{Key Words}

- corticotropin-releasing hormone receptor 1

- colitis-associated cancer (CAC)

- macrophages

- NFKB

\section{Introduction}

Colorectal cancer (CRC) is one of the most common forms of malignant tumor in developed countries, and patients with inflammatory bowel diseases, such as Crohn's disease and ulcerative colitis (UC), are at higher risk for developing CRC than the general population (Eaden et al. 2001). Indeed, emerging evidence suggest that uncontrolled inflammation is a major risk factor for the development of cancer (Grivennikov et al. 2010). The first study about links between cancer and inflammation was reported in the 19th century, on the basis of observations that tumors often arose at sites of chronic inflammation and that inflammatory cells were present in biopsied

Published by Bioscientifica Ltd. 
samples from tumors (Balkwill \& Mantovani 2001). It is now evident that inflammatory cells have powerful effects on tumor development. Early in the neoplastic process, cells such as neutrophils, macrophages, and lymphocytes are powerful tumor promoters, producing an attractive environment for tumor growth, facilitating genomic instability and promoting angiogenesis. The inflammatory cells along with the chemokines and cytokines produced could regulate the growth, migration, and differentiation of all cell types and finally influence the whole tumor organ (Shacter \& Weitzman 2002, Karin et al. 2006, Lin \& Karin 2007).

Particular emphasis has been given on the roles of the master transcription factors such as nuclear factor kappa-light-chain-enhancer of activated B cells (NFKB) and STAT3 in the development of colitis-associated cancer (CAC). In immune cells, NFאB induces the transcription of genes that encode proinflammatory cytokines, which can act in a paracrine manner on mucosal epithelial cells (Greten et al. 2004). What is more, in tumorigenic cells, both NFאB and STAT3 control apoptosis and STAT3 can also enhance proliferation (Grivennikov et al. 2009, Pickert et al. 2009). Another key player in apoptosis is the BCL2 family of proteins, which can be divided into either anti-apoptotic members (BCL2, BCL-XL, BCL-W, A1, and MCL1) or pro-apoptotic members (BAX, BID, BAD, BAK, BIC, BOK, BCL-XS, and HRK) members (Reed 1996, Gross et al. 1999). Many studies proposed that the relative levels of the pro-apoptotic protein BAX and anti-apoptotic protein BCL2 within a cell determine whether the cell lives or dies in response to apoptotic signaling (Oltvai et al. 1993, Reed 1994).

Corticotrophin-releasing hormone (CRH) family neuropeptides perform many physiological and pathophysiological functions. This family consists of CRH and CRH-related peptides, urocortin (UCN1), UCN2 (stresscopin-related peptide), and UCN3 (stress-copin) (Vaughan et al. 1995). They develop their biological activities through two G-protein-coupled receptors, CRH receptor 1 (CRHR1) and CRH receptor 2 (CRHR2). CRH and UCN1 have a high affinity to CRHR1, whereas UCN2 and UCN3 exclusively bind to CRHR2 (Vaughan et al. 1995). Both CRHRs and their ligands distribute extensively in the CNS (Van Pett et al. 2000) and the periphery site including immune tissues and inflammatory sites (Radulovic et al. 1999). In the CNS, CRH modulates the synthesis and release of adrenocorticotropic hormone, which in turn stimulates the production of glucocorticoids, exerting anti-inflammatory effects (Bateman et al. 1989). However, recent findings have revealed that large quantities of peripheral CRH-related peptides function as proinflammatory factors (Webster et al. 1998, Elenkov \& Chrousos 1999, Zhu et al. 2011). Our previous data also demonstrated that UCN1 could increase lipopolysaccharide (LPS)-induced endothelial permeability by disrupting the VE-cadherin- $\beta$-catenin complex (Wan et al. 2013). Besides, UCN1 was found to increase pulmonary vascular permeability via mast cell infiltration and activation (Wu et al. 2006), and that mast cell activation and degranulation induced by UCN1 was mediated by increasing intracellular calcium concentration, which could be blocked by a selective CRHR1 antagonist (Wu et al. 2008). These proinflammatory actions of CRH family and its receptors are involved in a series of inflammatory diseases, including rheumatoid arthritis (Kohno et al. 2001), Hashimoto's thyroiditis (Scopa et al. 1994), and UC.

Early in 1990s, the CRH family and the receptors were found in the gastrointestinal system and were reported to be implicated in the actions of colitis (van Tol et al. 1996). In 1995, it was proved that CRH was present in the colonic mucosa of patients with UC and acted as a proinflammatory agent modulating the intestinal immune system (Kawahito et al. 1995). Furthermore, UCN1 was found to be synthesized and secreted in plasma cells, which was correlated with the severity of inflammation in colonic mucosa with UC (Saruta et al. 2004). In addition, in the mouse model of DSS-induced colitis, CRHR1 deficiency was observed to contribute to the relief of intestinal inflammation (Im et al. 2010). Taken together, these studies suggest that activation of CRHR1 by CRH or UCN1 exerts an effect of exacerbating intestinal inflammation. However, none of these earlier studies examined the detailed effects of CRHR1 on colitis-associated tumorigenesis.

In this study, we sought to investigate the role of CRHR1 in the regulation of tumorigenesis in a mouse model of CAC.

\section{Materials and methods}

\section{Human colorectal tissue specimens}

Human colon samples were obtained from subjects enrolled in the First Affiliated Hospital of Nanjing Medical University (Nanjing, China). Colon mucosal biopsies were collected at the time of colonoscopy and stored in formalin. Matched mucosal biopsies were obtained and sent to the pathology department for routine histological evaluation. Histological examination from a total of seven subjects diagnosed with colorectal carcinoma were analyzed.

Published by Bioscientifica Ltd. 


\section{Animal models}

Crhr1 heterozygote $\left(C r h r 1^{+/-}\right)$mice (129-Crhr $\left.{ }^{\text {tm1Klee }}\right)$ were purchased from The Jackson Laboratory (Bar Harbor, ME, USA) and their genetic background is 129S4/SvJae and C57BL/6. Crhr1-deficient (Crhr1 $\left.{ }^{-/-}\right)$mice and their WT $\left(\mathrm{Crhr} 1^{+/+}\right)$littermates ( $\mathrm{M}$ and F, 8-12 weeks) were obtained from heterozygous breedings. All mice were housed under controlled conditions (temperature $22^{\circ} \mathrm{C}$; $12 \mathrm{~h}$ light:12 h darkness cycle; lights on at $0700 \mathrm{~h}$ ) and were given free access to standard laboratory pellet formula and tap water. Crhr1 ${ }^{+/+}$and $C r h r 1^{-/-}$mice were used for experiments while $\mathrm{Crhr} 1^{-/+}$were used for further production and excessive mice were discarded. All experiments were carried out in accordance with the official recommendations of the Chinese Community Guidelines. CAC was induced as described previously (Greten et al. 2004). Briefly, mice were injected i.p. with $10 \mathrm{mg} / \mathrm{kg}$ azoxymethane (AOM; Sigma) on day 0 and after 5 days, received drinking water containing 3\% dextran sodium sulfate (DSS; MP Biomedicals, Irvine, CA, USA) for 5 days followed by regular water drinking for 14 days. This cycle was repeated twice and mice were killed on the 80th day (Fig. 1A).

\section{Histopathological analysis}

Formalin-preserved colon sections were processed and embedded in paraffin by standard techniques. Longitudinal sections of $5 \mathrm{~mm}$ thick were stained with hematoxylin and eosin (H\&E) and examined by a pathologist blinded to the experimental groups. Colitis scores were assigned based on the extent and severity of inflammation, ulceration, and hyperplasia of the mucosa, as described by Zaki et al. (2011). For immunohistochemistry, formalin-fixed paraffin-embedded tissues were cut into $4 \mathrm{~mm}$ sections and slides were stained with antibodies against the CRH (Sigma), UCN1 (Abcam, Cambridge, MA, USA), CRHR1 (Novus Biologicals, Cambridge, MA, USA), macrophage marker F4/80 (Abcam), B cell marker CD20 (Abcam), and T cell marker CD3 (Abcam).

A
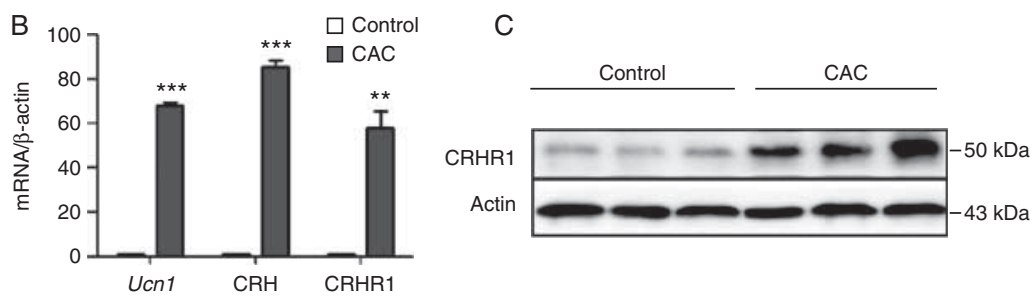

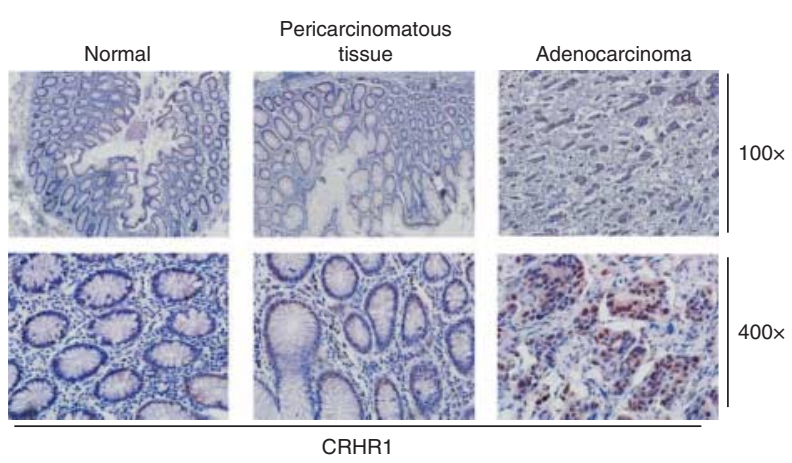

E

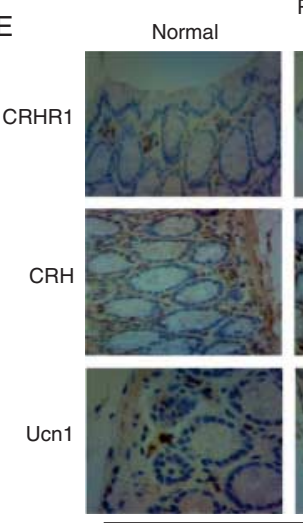

Pericarcinomatous

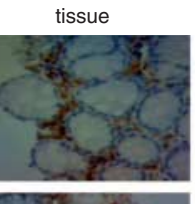

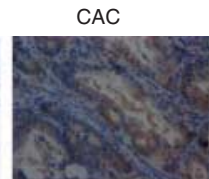
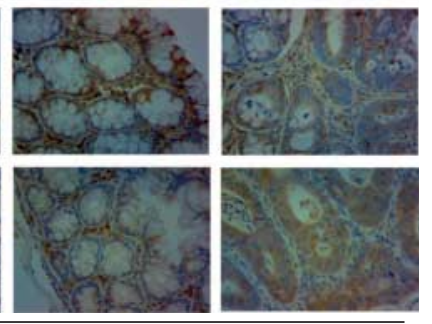

$400 x$

\section{Figure 1}

Expression of CRHR1 and its ligands increased in the mice with colitisrelated cancer induced by AOM and DSS. (A) Schematic overview of the CAC regimen. Crhr $1^{+1+}$ littermates were injected with $\mathrm{AOM}$ followed by three cycles of $3 \%$ DSS in drinking water. Colons were analyzed on day 80 . (B) Real-time PCR analysis for mRNA of urocortin (Ucn1), corticotrophinreleasing hormone $(\mathrm{CRH})$, and $\mathrm{CRH}$ receptor 1 (CRHR1) in colon from CAC mice and $\mathrm{Crhr} 1^{+/+}$littermate ( $n=8$ mice per group). (C) Western blotting analysis for CRHR 1 protein in colons from CAC and control mice $(n=8$ mice per group). (D) Expressions of CRHR1 were determined by immunohistochemistry from the colon samples of CAC patients. (E) Expressions and localizations of UCN1, CRH, and CRHR1 were determined by immunohistochemistry from CAC and control mice. Data represented means \pm s.E.M.; $* * P<0.01, * * * P<0.001$ vs $C r h r 1^{+\prime+}$. http://erc.endocrinology-journals.org DOI: 10.1530/ERC-14-0239
(C) 2014 Society for Endocrinology Printed in Great Britain 


\section{Quantitative real-time PCR}

Total RNA from the mouse colon was isolated using TRIzol (Invitrogen) according to the manufacturer's protocol, and an equal amount of RNA $(2 \mu \mathrm{g})$ was transcribed into cDNA using an RT reagent kit (iTaq, Hercules, CA, USA). Subsequently, quantitative real-time PCR was carried out with SYBR Green oligonucleotides (iTaq) using a 7300 Fast Real-Time PCR instrument (Applied Biosystems). The level of expression was calculated based on the PCR cycle number $\left(C_{\mathrm{T}}\right)$ at which the exponential growth in fluorescence from the probe passed a certain threshold value $\left(C_{\mathrm{T}}\right)$. Relative gene expression was determined by differences in the $C_{\mathrm{T}}$ values of the target genes after normalization to the RNA input level, using the $C_{\mathrm{T}}$ value of ACTIN. Relative quantification was represented by standard $2^{-\Delta C_{\mathrm{T}}}$ calculations. $\Delta C_{\mathrm{T}}=\left(C_{\mathrm{T} \text {-target gene }}-C_{\mathrm{T} \text {-ACTIN }}\right)$. Each reaction was carried out in triplicate. Primer sequences are given in Table 1.

\section{Cell amount analysis}

Briefly, blood was sampled from retroorbital sinus in a tube containing EDTA-2K buffer, and stained for macrophagocyte cell markers CD11b + and CD11c- (e-Bioscience, San Diego, CA, USA) and then analyzed with flow cytometry (BD Biosciences, Franklin Lakes, NJ, USA).

\section{PBMC isolation}

Mice were anesthetized in a diethyl ether atmosphere and blood was collected by cardiac paracentesis in a tube containing EDTA-2K buffer. Anti-coagulated blood was layered onto mononuclear separating medium (Haoyang, Tianjin, China) and peripheral blood mononuclear cells (PBMC) were purified by gradient centrifugation $(400 \boldsymbol{g}$, $30 \mathrm{~min}$ ) according to the manufacturer's recommendations.

\section{Immunoblotting analysis}

Equal amounts of protein from colon were subjected to SDS-PAGE analysis and immunoblotting using antiCRHR1 antibody (1:1000, overnight in $4{ }^{\circ} \mathrm{C}$; Novus Biologicals), anti-p-NFאB antibody (1:1000, overnight in $4{ }^{\circ} \mathrm{C}$; Cell Signaling Technology, Danvers, MA, USA), antiNF $\kappa$ B antibody $\left(1: 1000\right.$, overnight in $4{ }^{\circ} \mathrm{C}$; Cell Signaling Technology), anti-p-STAT3 antibody (1:1000, overnight in $4{ }^{\circ} \mathrm{C}$; SAB), anti-STAT3 antibody (1:1000, overnight in $4^{\circ} \mathrm{C}$; Cell Signaling Technology), anti-BCL2 antibody (1:1000, overnight in $4{ }^{\circ} \mathrm{C}$; Cell Signaling Technology), anti-BAX antibody (1:1000, overnight in $4{ }^{\circ} \mathrm{C}$; Abcam), anti- $\beta$-ACTIN antibody (1:5000, overnight in $\left.4{ }^{\circ} \mathrm{C}, \mathrm{SAB}\right)$, and anti-histone antibody $\left(1: 10000\right.$, overnight in $4{ }^{\circ} \mathrm{C}$; Abmart, Shanghai, China). Western blotting analysis was carried out as described previously (Xu et al. 2009).

Table 1 Summary of qRT-PCR of primer sequences

\begin{tabular}{|c|c|c|}
\hline Name & Sequences & GenBank accession number \\
\hline CRHR1 & $\begin{array}{l}\text { Sense: GGAACCTCATCTCGGCTTTCA } \\
\text { Antisense: GTTACGTGGAAGTAGTTGTAGGC }\end{array}$ & NM_007762.4 \\
\hline Urocortin & $\begin{array}{l}\text { Sense: TCTTGCTGTTAGCGGAGCG } \\
\text { Antisense: TCGAATATGATGCGGTTCTGC }\end{array}$ & NM_021290.2 \\
\hline $\mathrm{CRH}$ & $\begin{array}{l}\text { Sense: CCTCAGCCGGTTCTGATCC } \\
\text { Antisense: GCGGAAAAAGTTAGCCGCAG }\end{array}$ & NM_205769.2 \\
\hline IL1 $\beta$ & $\begin{array}{l}\text { Sense: TGACCTGGGCTGTCCTGATG } \\
\text { Antisense: GGTGCTCATGTCCTCATCCTG }\end{array}$ & NM_008361.3 \\
\hline IL6 & $\begin{array}{l}\text { Sense: CTGCAAGAGACTTCCATCCAGTT } \\
\text { Antisense: GAAGTAGGGAAGGCCGTGG }\end{array}$ & NM_031168.1 \\
\hline IL10 & $\begin{array}{l}\text { Sense: GCTCTTACTGACTGGCATGAG } \\
\text { Antisense: CGCAGCTCTAGGAGCATGTG }\end{array}$ & NM_010548.2 \\
\hline $\mathrm{TNF} \alpha$ & $\begin{array}{l}\text { Sense: AGGCTGCCCCGACTACGT } \\
\text { Antisense: GACTTTCTCCTGGTATGAGATAGCAAA }\end{array}$ & NM_001278601.1 \\
\hline $\operatorname{cox} 2$ & $\begin{array}{l}\text { Sense: GGGTGTCCCTTCACTTCTTTCA } \\
\text { Antisense: TGGGAGGCACTTGCATTGA }\end{array}$ & NM_011198.3 \\
\hline $\mathrm{IFN} \gamma$ & $\begin{array}{l}\text { Sense: AAGCGTCATTGAATCACACCTG } \\
\text { Antisense: TGACCTCAAACTTGGCAATACTC }\end{array}$ & NM_008337.3 \\
\hline ACTIN & $\begin{array}{l}\text { Sense: ATGCTCCCCGGGCTGTAT } \\
\text { Antisense: CATAGGAGTCCTTCTGACCCATTC }\end{array}$ & NM_007393.3 \\
\hline
\end{tabular}

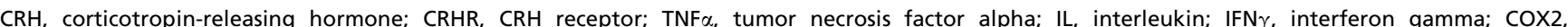
cycloxygenase 2 .

http://erc.endocrinology-journals.org DOI: 10.1530/ERC-14-0239 (c) 2014 Society for Endocrinology Printed in Great Britain
Published by Bioscientifica Ltd 


\section{In situ intestinal proliferation assay}

The number of proliferating cells in intestinal epithelium was determined using the immunoperoxidase staining protocol with the thymidine analog 5-bromo-2-deoxyuridine (BrdU, Sigma). In brief, a working solution of BrdU in PBS at $1 \mathrm{mg} / \mathrm{ml}$ was prepared and injected mice i.p. with $1 \mathrm{ml}(1 \mathrm{mg})$ of BrdU solution. Twenty-four hours later, colon tissues were collected, fixed in 10\% neutral buffered formalin, and embedded in paraffin. Immunohistochemistry was carried out using the BrdU In situ Detection Kit (BD Pharmingen, San Jose, CA, USA) as described earlier (Zaki et al. 2010).

\section{TUNEL staining}

The TUNEL procedure was performed using the in situ Cell Death Detection Kit (Roche Applied Science). Proteinase K (20 $\mu \mathrm{g} / \mathrm{ml}$, Sigma) was applied to the tissue sections for $15 \mathrm{~min}$ at room temperature. Endogenous peroxidase was blocked by incubation of the sections with $2 \% \mathrm{H}_{2} \mathrm{O}_{2}$ for $5 \mathrm{~min}$. The sections were incubated with the TdT enzyme for $2 \mathrm{~h}$ at $37^{\circ} \mathrm{C}$. Antidigoxin-peroxidase solution was applied for $30 \mathrm{~min}$, followed by exposure to diaminobenzidine (DAB) substrate for 3-5 min and counterstaining with hematoxylin.

\section{Statistical analysis}

Data were represented as mean \pm s.E.M. The difference in survival was shown by Kaplan-Meier plot. The log-rank test was used to compare significant survival difference. Statistical significance was determined by Student's $t$-test. A $P$ value $<0.05$ was considered statistically significant.

\section{Results}

\section{Expression of CRHR1 in the colon of mice and CRC patients}

To explore the role of CRHR1 in CAC development, $C r h r 1^{+/+}$mice were injected with a single dose of the DNA-methylating agent AOM followed by three rounds of oral administration of DSS to trigger chronic CAC (Fig. 1A) and the mice were fed with tap water as the controls. The quantitative real-time PCR showed that the expression of CRHR1 and its ligands (UCN1 and CRH) were obviously increased in the colon of CAC mice compared with controls (Fig. 1B) and similar results were observed at the protein level of CRHR1 by western blotting (Fig. 1C). As in the model of CAC mice, slices from CRC patients also displayed enhancement of CRHR1 expression in the carcinomatous tissues compared with normal and pericarcinomatous tissues (Fig. 1D). We further analyzed the localizations of CRHR1 using immunohistochemistry. Similarly, CRHR1 and its ligands were less expressed in the mucosal inflammatory cells of normal mice, while their expression were all upregulated in the CAC mice. Interestingly, CRHR1 was mainly located in inflammatory cells of pericarcinomatous area, while CRHR1 were mostly expressed in the pejorative epithelial cells in the tumor area (Fig. 1E). These results indicated that increased CRHR1 might have an important biological function during the development of CAC.

\section{CRHR1 deficiency contributed to the alleviation of colitis-associated tumorigenesis}

To dissect the exact effect of CRHR1 on CAC, $\mathrm{Crhr}^{-1-}$ mice were generated and we induced colon tumorigenesis with AOM and DSS as mentioned above. Changes in body weight were monitored daily throughout the study duration and colonic tumor burden was determined 80 days after AOM and DSS treatment. Mortality and weight loss were significantly reduced in $\mathrm{Crhr}^{-/-}$mice compared with $\mathrm{Crhr}^{+/+}$during the early stage of tumor induction (day 10 after AOM injection) (Fig. 2A and B). Consistently, $\mathrm{Crhr}^{-/-}$mice were markedly protected from AOM and DSS-induced tumorigenesis (Fig. 2C, D, E, and F).

\section{Decreased tumor burdens were associated with lower incidence of dysplasia and less inflammatory cytokines expression}

Histological examination revealed that $70 \%$ of $\mathrm{Crhr} 1^{+/+}$ mice developed high-grade dysplasia, of which $30 \%$ were classified as adenocarcinoma with invasive growth. By contrast, only $40 \%$ of $\mathrm{Crhr}^{-/-}$mice displayed high-grade dysplasia and no adenocarcinomas were observed in any of $\mathrm{Crhr1}^{-/-}$(Fig. 3A and B). Histological scores from the quantifications of ulceration, inflammation, and hyperplasia of the mucosa were significantly decreased in Crhr1 ${ }^{-/-}$mice (Fig. 3C and D). Besides, both mRNA and protein expression of proinflammatory cytokines, such as IL1 $\beta$, IL6, and TNF $\alpha$, were markedly lower, whereas the anti-inflammatory factor, IL10 was significantly higher in $\mathrm{Crhr}^{-/-}$than that in $\mathrm{Crhr} \mathrm{1}^{+/+}$mice (Fig. 3E). We next analyzed the expressions of multiple cytokines and tumorigenic factors cycloxygenase 2 (COX2) and interferon gamma (IFN $\gamma$ ) in colon tissue as these factors often

Published by Bioscientifica Ltd 

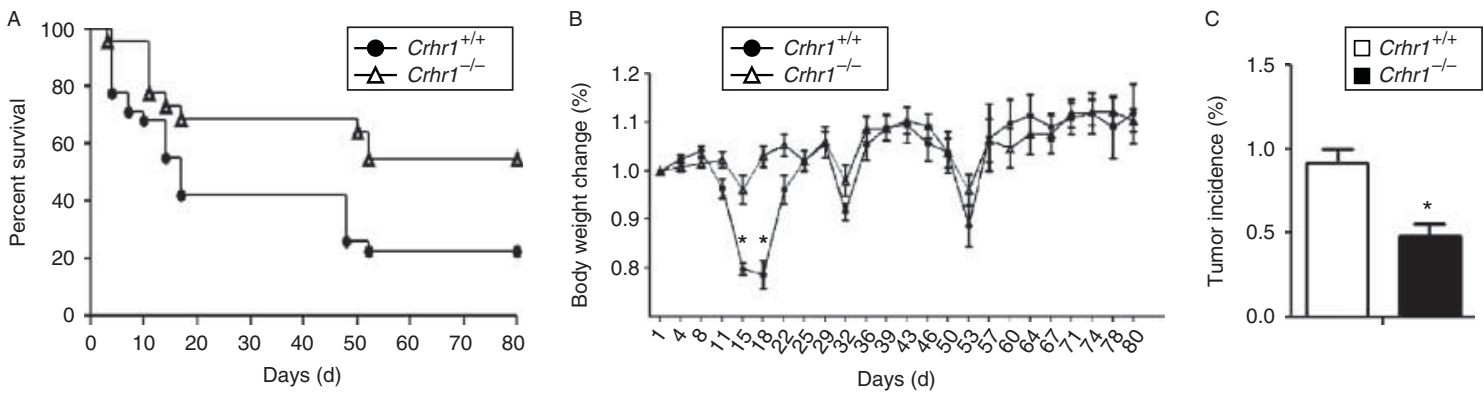

D

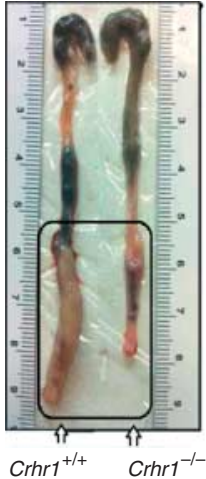

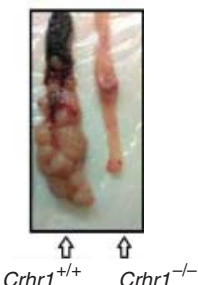
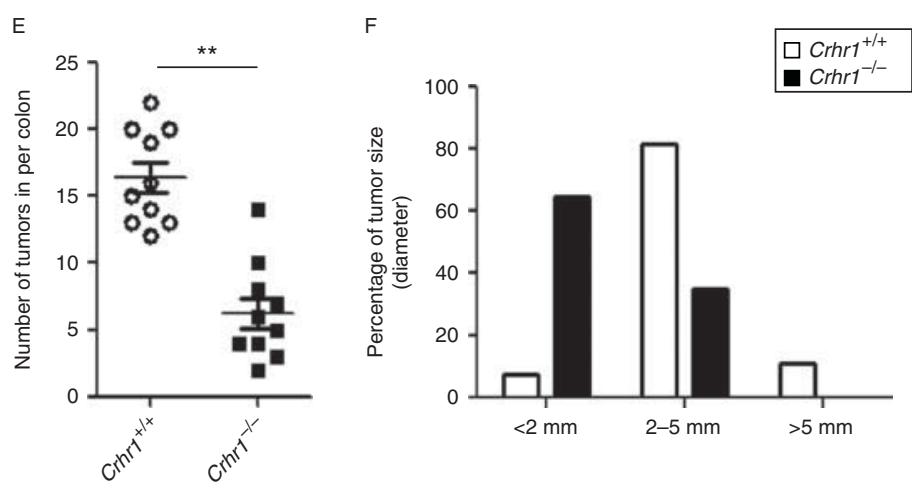

Figure 2

Decreased CAC tumorigenesis in Crhr1-deficient $\left(\mathrm{Crhr}^{-1-}\right)$ mice. (A) Survival rate of $\mathrm{Crhr}^{+/+}$mice $(27.27 \%)$ and $\mathrm{Crhr}^{-1-}$ mice $(47.62 \%)$ were shown by the Kaplan-Meier plot. The log-rank test indicated there were significant survival differences between $\mathrm{Crhr}^{-1-}(n=21$ mice per group) and WT (Crhr1 $\left.{ }^{+/+}\right)(n=33$ mice per group) $P=0.001$. (B) Body weight loss was shown. Day $15\left(\mathrm{Crhr}^{+1+}: 79.77 \% \pm 0.389 \% ; \mathrm{Crhr}^{-1-}\right.$ : $96.13 \% \pm 0.775 \%)$ and day $18\left(\mathrm{Crhr}^{+1+}: 78.6 \% \pm 1.22 \% ; n=11 ; \mathrm{Crhr}^{-1-}\right.$ :

drive tumorigenesis. Similarly, mRNA levels of Cox 2 and If $n \gamma$ were markedly reduced in $C r h r 1^{-/-}$mice than those in $C r h r 1^{+/+}$mice (Fig. 3F). These results suggested that CRHR1 activation increased the risk of tumorigenesis with enhanced inflammation and hyperplasia, and a higher incidence of dysplasia.

\section{CRHR1 was critical in tumor induction during the early stage of CAC}

As described earlier, the weight loss and survival rate differences between $C r h r 1^{+/+}$and $C r h r 1^{-/-}$mice were detected at the early stage of tumorigenesis. These results promoted us to hypothesize that CRHR1 influencing on tumorigenesis occur early from the onset of tumorigenesis. To characterize this possibility in detail, we collected the colons from mice killed at day 10, 15, and 25 after AOM injection. Interestingly, colons from $\mathrm{Crhr} 1^{-/-}$mice were significantly longer than those from $\mathrm{Crhr} 1^{+/+}$mice after day 15 (Fig. 4A and B). In addition, histopathological
$103.96 \% \pm 0.60 \% ; n=17) .{ }^{*} P<0.05$ vs $C r h r 1^{+/+}$. (C) The incidence of tumor was analyzed (Crhr1 ${ }^{-1-}: n=17$ mice per group; $C r h r 1^{+/+}: n=11$ mice per group). (D) Mice were killed to determine tumor development in the colon on day 80 . (E) Numbers of tumors in the whole colon were counted ( $n=6$ mice per group) $\left.\mathrm{Crhr} 1^{+/+}: 16.4 \pm 0.35 ; \mathrm{Crhr}^{-1-}: 6.3 \pm 0.36\right)$. (F) Diameter of the tumors was measured at the end of the study ( $n=6$ mice per group). Data represented mean \pm s.E.M.; $* P<0.05, * * P<0.01$ vs $C r h r 1^{+1+}$.

analysis revealed more severely damaged colonic mucosa with extensive loss of crypt structures and epithelial cell denudation, larger areas of ulceration, and more extensive infiltration of inflammatory cells in $\mathrm{Crhr} 1^{+/+}$group (Fig. 4C), which was also reflected in the pathological assessment of colitis severity scores (Fig. 4D and E). Taken together, these results suggested that CRHR1 played a critical role during the early stage of colitis-associated tumorigenesis, because from day 25 onwards, occurrence of tumor formation was observed as described above.

Inflammatory cell activity was decreased in $\mathrm{Crhr}^{-/-}$mice Previous studies suggested that CRHR1 was a key inflammation regulator (Xu et al. 2009, Zocco et al. 2010). To further confirm the effect of CRHR1 on inflammation in terms of CAC, inflammatory cytokine production was analyzed during day 0 to day 25. Not surprisingly, the mRNA expression for $I l 1 \beta, I l 6$, and Tnf $\alpha$ was decreased, while $I l 10$ was increased in $C r h r 1^{-/-}$mice

Published by Bioscientifica Ltd. 


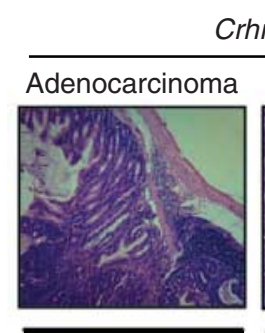

$100 x$

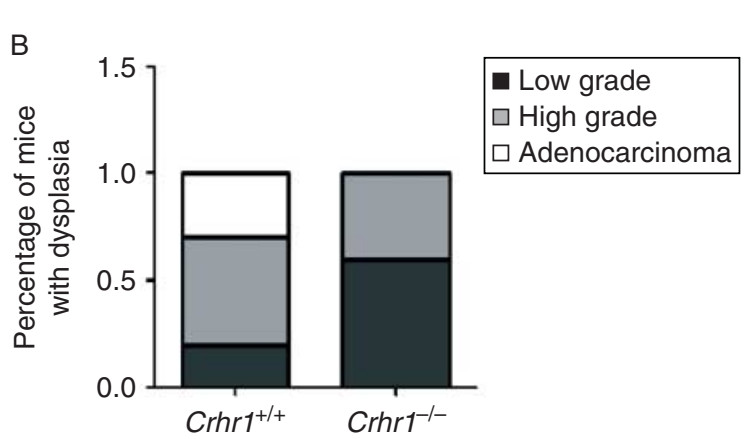

C

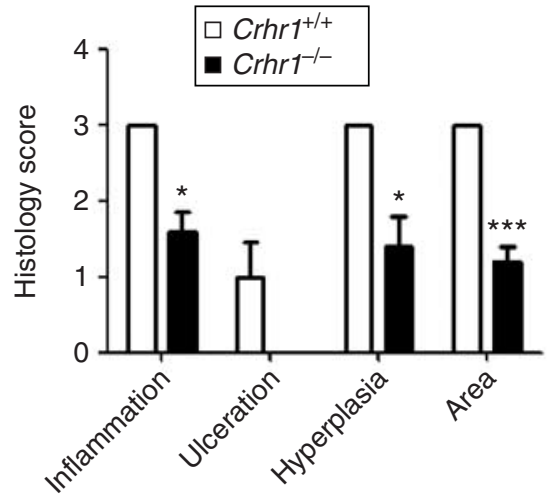

D

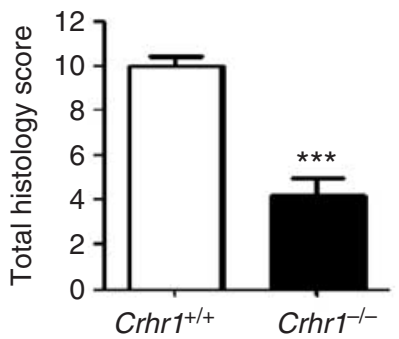

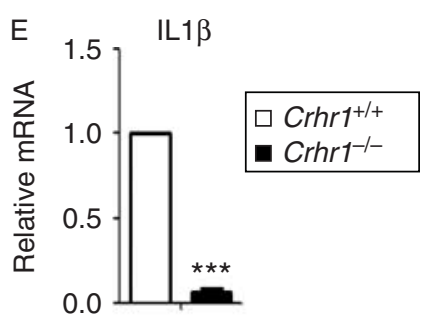
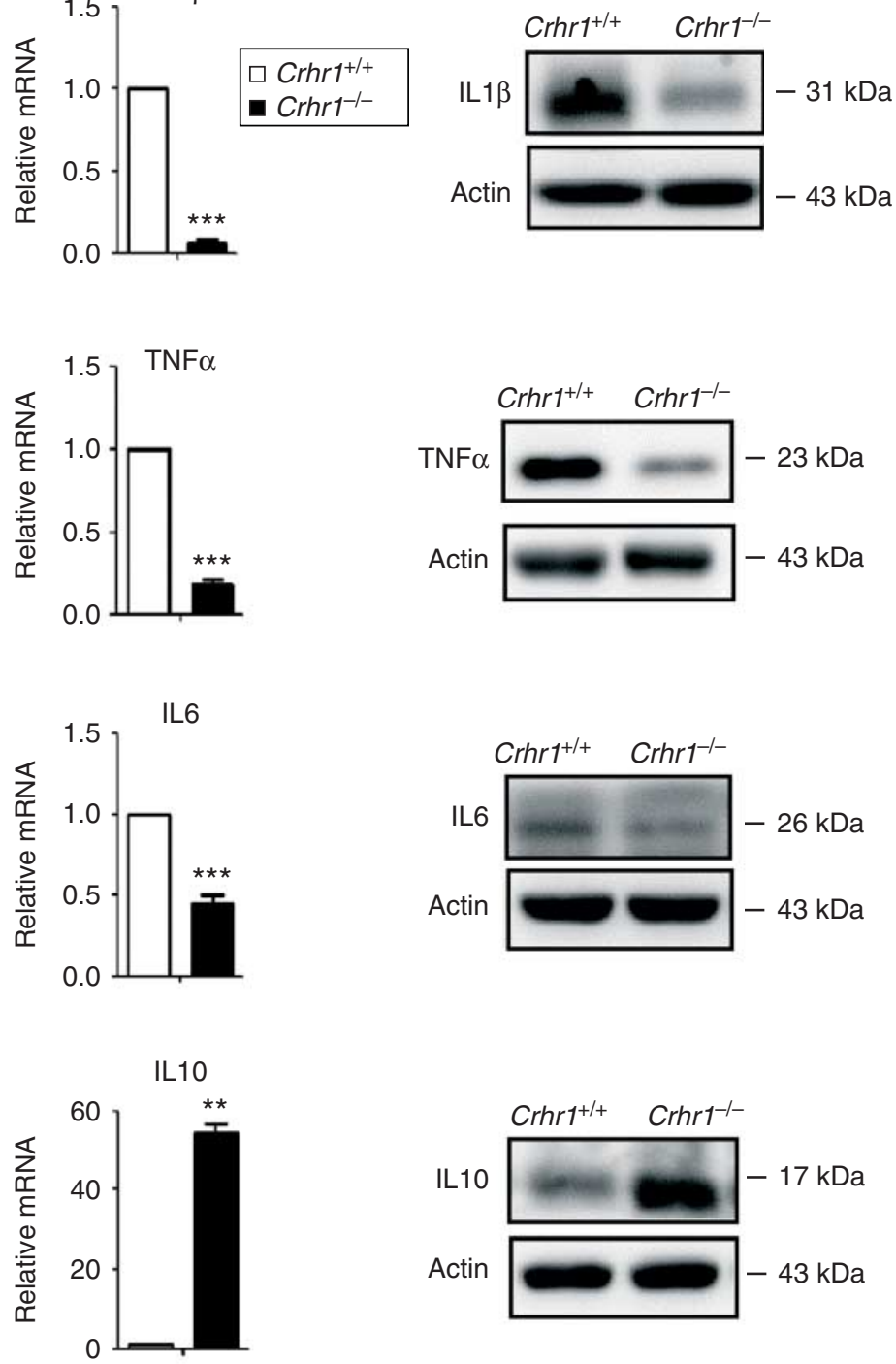

$\mathrm{F}$

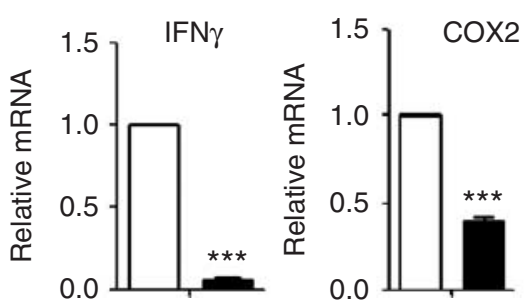

Figure 3

Alleviated CAC severity in $\mathrm{Crhr}^{-1-}$ mice attributed to reduced inflammation response. (A) Representative images of H\&E staining of colon sections showing dysplasia. (B) Overall grading of dysplasia in each genotype. (C) H\&E stained sections were scored for inflammation, ulceration, hyperplasia, and inflamed area, and determined in a double-blind manner. (D) Total histology scores from $\mathrm{Crhr}^{+/+}$mice (scores $\left.=10+0.20\right)$ and $\mathrm{Crhr}^{-1-}$ mice (scores $=4.2 \pm 0.33$ ). (E) Expression of IL1 $\beta$, IL6, IL10, and TNF $\alpha$ in colon were analyzed. (F) RNA for expression analysis of IFN $\gamma$ and COX2 by real-time PCR. Data represented mean \pm s.E.M.; $n=5-7$ mice per group; $* P<0.05, * * P<0.01$, $* * * P<0.001$ vs $\mathrm{Crhr}^{+/+}$littermates. http://erc.endocrinology-journals.org DOI: 10.1530/ERC-14-0239
(C) 2014 Society for Endocrinology Printed in Great Britain 

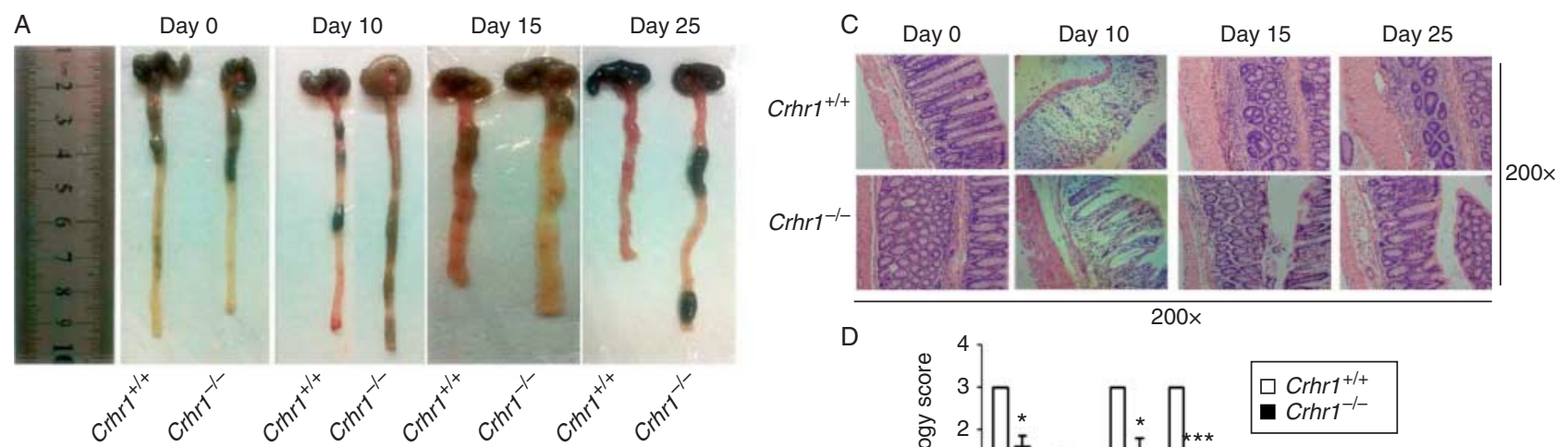

B
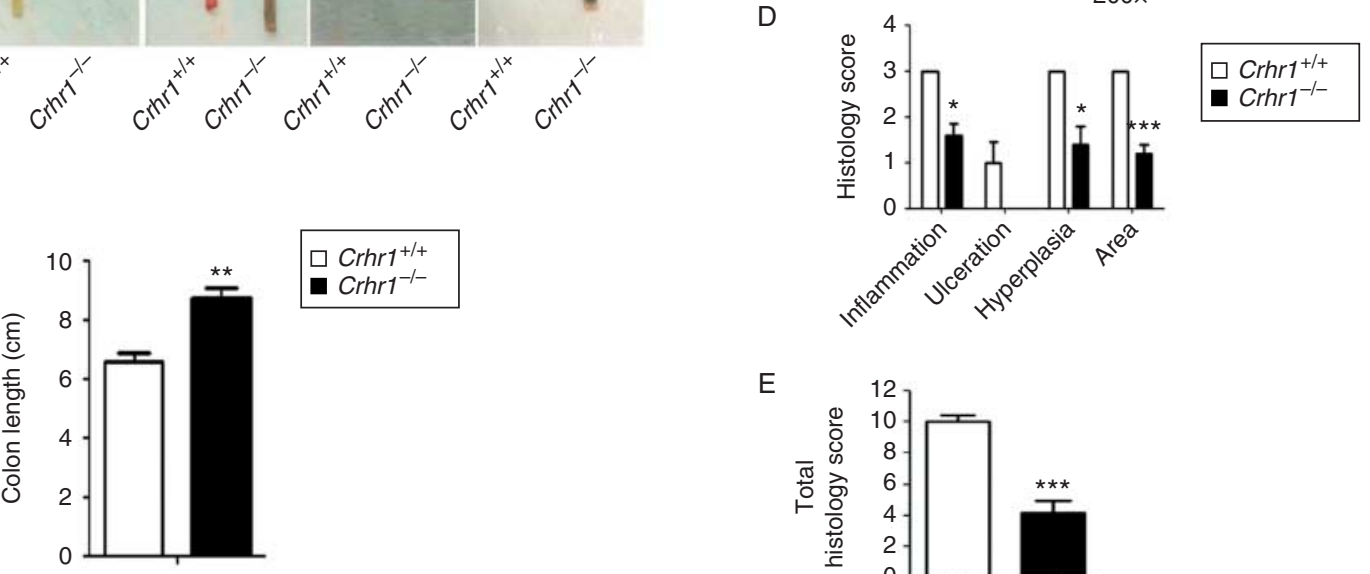

$E$

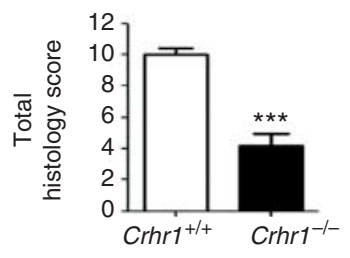

Figure 4

CRHR1 induced tumor at the early stage of tumorigenesis. (A, B, and C) Mice were killed at day $0,10,15$, and 25 after $A O M$ injection. (A and $B$ ) Changes in colon length was monitored. (C) Mucosal histology was

after day 10 (Fig. 5A). We therefore hypothesized that the loss of CRHR1 may protect from colitis-associated tumorigenesis by attenuating immune cell activation and inflammatory responses in response to DSS treatment. To testify this possibility, immunohistochemical analysis was used to characterize the immune cell associated with the induction of hyperinflammatory responses in the colon. During inflammation response, more lymphocytes and macrophages infiltrated into the colon mucosa of $\mathrm{Crhr}^{+/+}$ mice (Fig. 5B). To determine the inflammatory cell type regulated by CRHR1, immunostained mucosa of large intestine with the markers of macrophage, B cells, T cells, and anti-CRHR1 was examined. The results showed that CRHR1 was mostly detected in macrophages but not in B cells and T cells (Fig. 5C). Flow cytometry analysis showed that lower levels of macrophages in the whole peripheral blood of $\mathrm{Crhr}^{-/-}$mice than in those of $\mathrm{Crhr}^{+/+}$mice from day 10 (Fig. 5D). To further characterize whether CRHR1 deficiency could affect the secretion of inflammatory cytokines, mononuclear cells (macrophage precursors) collected from the whole peripheral blood of $\mathrm{Crhr}^{+/+}$ and $\mathrm{Crhr}^{-/-}$mice were equally seeded into plate and stimulated with LPS for $6 \mathrm{~h}$, and the inflammatory factors

examined by H\&E staining. ( $D$ and $E$ ) Colitis severity scores were determined at day 25 in a double-blind manner. Data represented mean \pm s.E.M.; $n=9$ per group; ${ }^{*} P<0.05,{ }^{*} P<0.01,{ }^{* *} P<0.001$ vs $C r h r 1^{+/+}$littermates.

in the supernatant were monitored using ELISA. The ELISA analysis showed significantly less IL6 and TNF $\alpha$ released from mononuclear cells in $\mathrm{Crhr}^{-1-}$ mice, but no difference in the levels of IL1 $\beta$ and IL10 between $\mathrm{Crhr}^{-1-}$ and $\mathrm{Crhr}^{+/+}$mice (Fig. 5E).

Thus, these results suggested that less susceptible tumorigenesis of $\mathrm{Crhr1}^{-/-}$was partly owing to weaker inflammatory response in inflammatory cells, especially the macrophages.

\section{CRHR1 regulated colonic cells survival and proliferation through NFKB and STAT3 signals}

The expression of tumorigenic and proinflammatory genes is modulated by signal transduction pathways mediated by $\mathrm{NF \kappa B}$ and STAT proteins. To understand whether these pathways and molecules were deregulated in the presence of CRHR1, we examined the activation of NFKB and STAT signaling pathways by western blotting. Indeed, after AOM/DSS treatment, significantly higher activation levels of NFKB (p65 phosphorylation) and phosphorylated STAT3 were observed in the colon tissue of $\mathrm{Crhr}^{+/+}$mice at day 25 after AOM injection (Fig. 6A).

Published by Bioscientifica Ltd. 

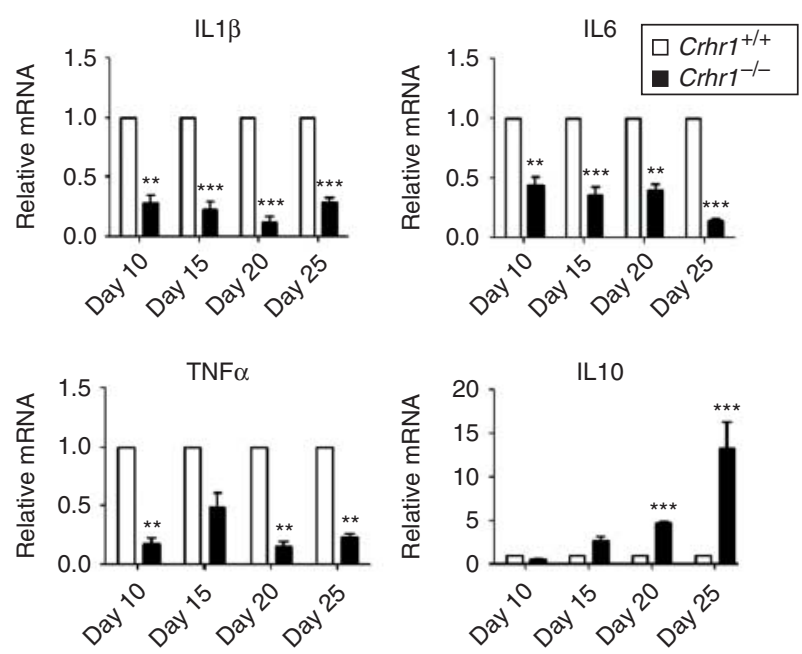

B

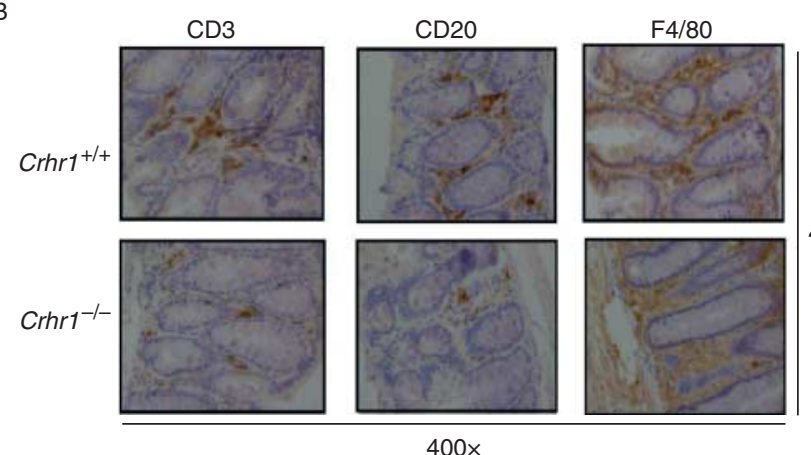

C
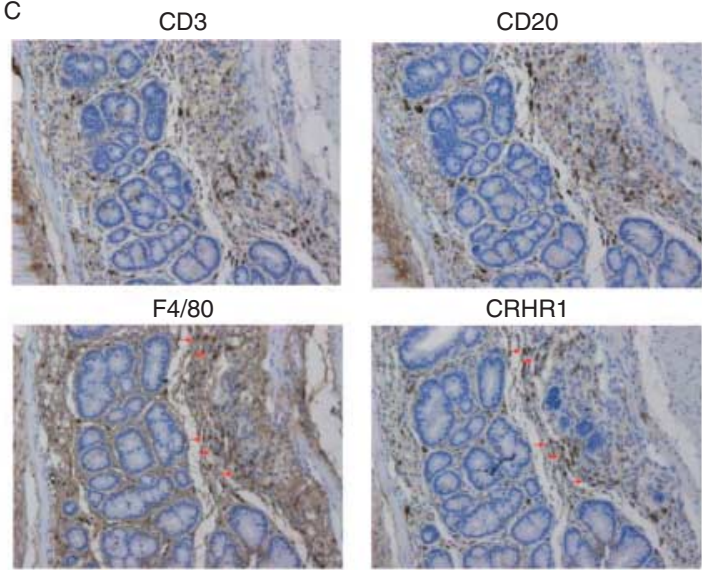

CRHR1

$400 x$

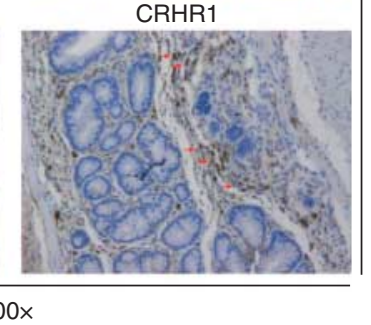

D

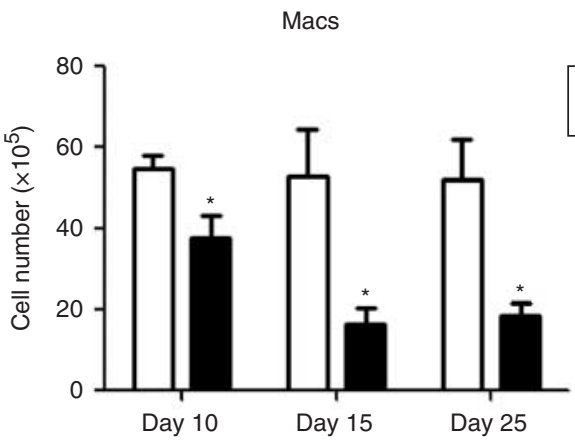

Figure 5

The presence of CRHR1 led to increased inflammatory cell activation in colon tissue. (A) Real-time PCR was carried out to detect the expression of IL1 $\beta$, IL6, IL10, and TNF $\alpha$ in the colons collected from day $0,10,15$, and 25 after AOM injection. (B) Colon tissue collected at day 25 was immunostained for the macrophage marker F4/80, B cell marker CD20, and T cell marker CD3. (C) Mucosa of large intestines (collected at day 25) was stained

Besides, increased amounts of p65 were detected in the nucleus of $\mathrm{Crhr} 1^{+/+}$colonic cells (Fig. 6B). Hyperactivation of these inflammatory pathways is associated with an inhibited apoptosis and increased proliferation of epithelial cells. Indeed, immunohistochemical determination of BrdU-staining cells and phosphorylated STAT3expressing cells in the crypts demonstrated a much weaker cell proliferation in $\mathrm{Crhr} 1^{-/-}$mice killed at day 80 (Fig. 6C). The number of TUNEL-positive cells in colon tissue of $C r h r 1^{+/+}$mice was markedly less than that of $C r h r 1^{-/-}$mice at day 80 (Fig. 6D). Besides, the protein expression of the anti-apoptotic protein BCL2 was decreased, whereas the pro-apoptotic protein BAX was increased in the colon of Crhr $1^{-/-}$mice at day 80 (Fig. 6D). Taken together, these results suggested that CRHR1 activation enhanced the proliferation of colonic cells and increased their resistance with markers of macrophage, B cells, T cells, and anti-CRHR1 (red arrow head indicates co-localization of CRHR1 and macrophages). (D) Peripheral blood from $\mathrm{Crhr}^{+/+}$and $\mathrm{Crhr}^{-1-}$ mice killed at day 10, 15, and 25 were analyzed by flow cytometry after staining for macrophages marker (Macs, CD11b + CD11c - ). Data represented mean \pm s.E.M.; $n=5-7$ mice per group; $* P<0.05, * * P<0.01, * * * P<0.001$ vs $C r h r 1^{+1+}$ littermates.

to apoptosis through NFкB and STAT3 signals, implying a role of CRHR1 in tissue regeneration.

\section{Discussion}

Recent studies have documented that CRH family peptides and their receptors participated in the regulation of colitis. In this study, we have explored the effect of CRHR1 on CAC using a Crhr1-deficient mouse model. To our knowledge, it is the first study to demonstrate that CRHR1 plays a key role in the development of CAC.

In this study, we propose that the enhanced tumorigenesis may be due to increased inflammatory response via CRHR1. Our interpretation is based on several evidences. First, we demonstrated that CRHR1 and its specific ligands CRH and UCN1 were mainly expressed in

Published by Bioscientifica Ltd 
A
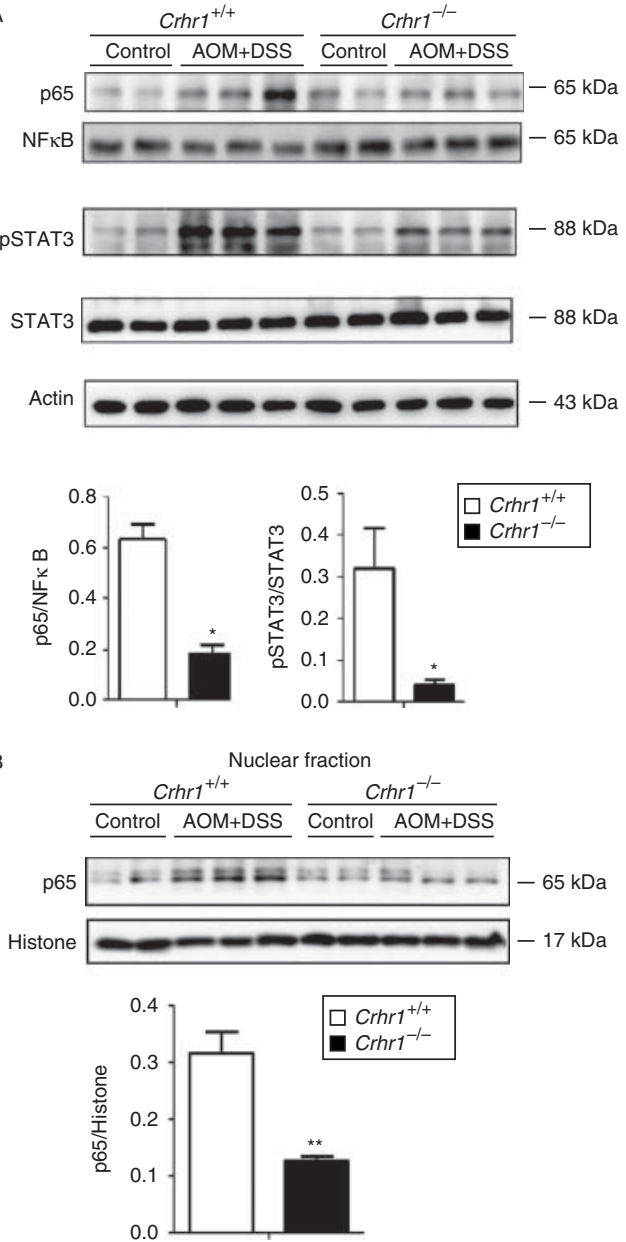

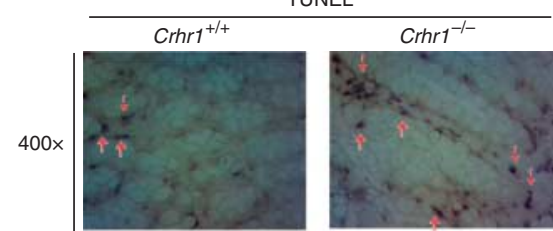

TUNEL
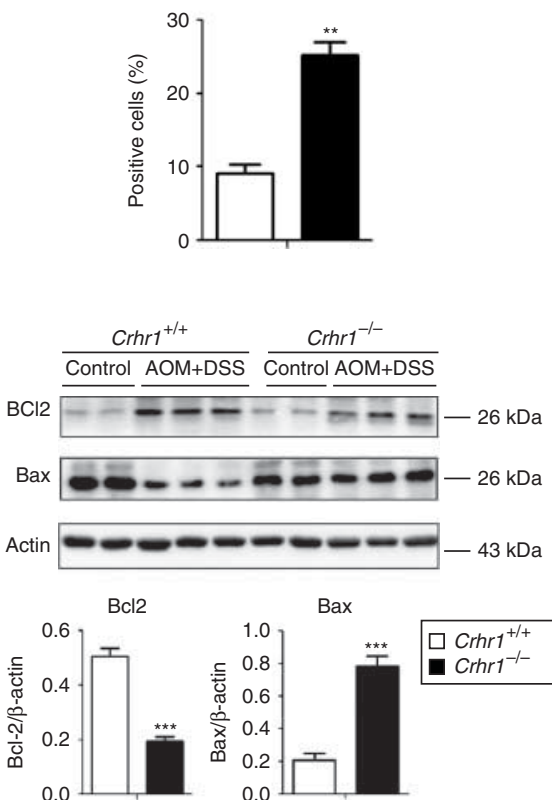

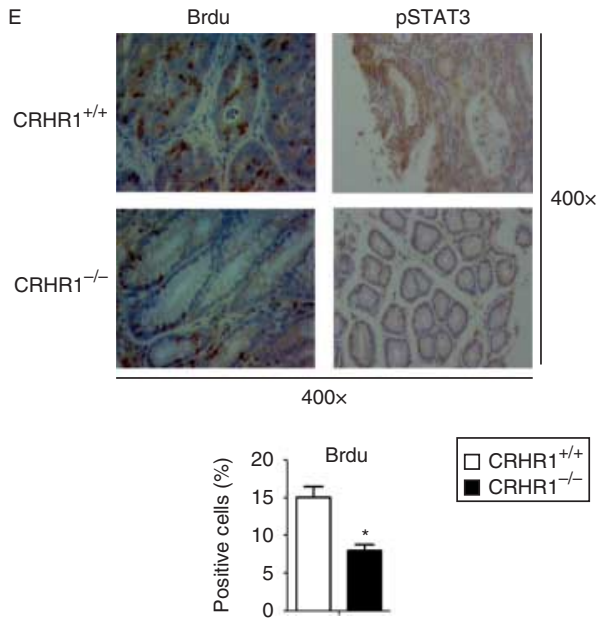

Figure 6

CRHR1 regulated cell proliferation and apoptosis in the colon through $\mathrm{NF} \kappa \mathrm{B}$ and STAT3 signals. (A) Colons from $\mathrm{Crhr}^{-1-}$ and $\mathrm{Crhr} 1^{+/+}$mice at day 25 were analyzed for phosphorylation of p65 and STAT3 by western blotting and densitometric analysis of band intensity of $\mathrm{p} 65$ and $\mathrm{p}$-STAT3 relative to NF $\kappa B$ and STAT3. (B) Western blotting analysis of p65 in nuclear fraction and densitometric analysis of band intensity of $\mathrm{p} 65$ relative to histone. (C) Number Printed in Great Britain of TUNEL-positive cells at day 80 after injecting AOM (red arrow head indicates apoptotic cells). (D) Colons from $\mathrm{Crhr}^{-1-}$ and $\mathrm{Crhr}^{+/+}$mice at day 80 were analyzed for BCL2 and BAX and the densitometric analysis of them. (E) Number of BrdU-positive cells and p-STAT3 positive cells at day 80 after injecting AOM. Data represented mean \pm s.E.M.; $n=5$ mice per group; ${ }^{\star} P<0.05,{ }^{*} P<<0.01,{ }^{* * *} P<0.001$ vs $C r h r 1^{+/+}$littermates. 
inflammatory cells. Second, Crhr1 ${ }^{+/+}$mice were more susceptible to colitis induced by DSS. Moreover, higher levels of proinflammatory factors and more inflammatory cell infiltration were detected in $\mathrm{Crhr}^{+/+}$mice. Last but not the least, the status of tumorigenesis was highly in line with the severity of colon inflammation. We found that $\mathrm{Crhr} 1^{-/-}$mice displayed a much lower incidence of tumorigenesis. The mortality and weight loss were significantly reduced in $\mathrm{Crhr}^{-/-}$mice. Besides, lighter tumor burdens and less high-grade dysplasia were also observed. Histological scores for the quantifications of ulceration, inflammation, and hyperplasia of the mucosa were markedly decreased in $\mathrm{Crhr}^{-/-}$mice. Taken together, our data provide a convincing evidence for the participation of CRHR1 in CAC.

As inflammation plays a critical role in tumorigenesis (Grivennikov et al. 2010), nearly all tumors are surrounded by inflammatory and immune cells, which produce cytokines and other factors that promote tumor growth and survival. CRHR1 had long been reported to be activated in immune cells, such as lymphocytes, monocytes, and macrophages. In our study, CRHR1 was mostly detected in macrophages, and much less macrophages infiltrated into the colon of $\mathrm{Crhr}^{-/-}$mice compared with $\mathrm{Crhr}^{+/+}$mice. In agreement with our data, in colonic biopsies of UC patients, $79 \%$ of CRHR1-immunoreactive (IR) cells in colonic lamina propria occurred in macrophages and CRHR1 IR macrophages were significantly increased compared with healthy subjects (Yuan et al. 2012). Furthermore, several studies have reported that CRHR1 and CRH exerted their biological effect on macrophages in in vitro experiments (Audhya et al. 1991, Tsatsanis et al. 2007). Thus, we proposed that CRHR1 exerted its pro-inflammatory effect through activation of macrophages in the CAC model.

For more detailed mechanism, key inflammatory mediators in the colon were detected: IL1 $\beta$, IL6, TNF $\alpha$, and COX2 are circulating cytokines that known to be secreted from a number of different cells including activated macrophages (Rankin 2004). A growing body of evidence suggests that activated macrophages in human colorectal tumors produce tumor-promoting cytokines such as IL6 and TNF $\alpha$ and chemokines such as KC, MIP2, COX2, and NOS2 (Qian \& Pollard 2010). Not surprisingly, our results showed the expression of IL1 $\beta$, IL6, TNF $\alpha$, and COX2 was drastically decreased in $\mathrm{Crhr} \mathrm{1}^{-/-}$CAC model. However, different from the proinflammatory factors, the expression of IL10 was found to be enhanced in $\mathrm{Crhr} 1^{-/-}$ mice. As the classical anti-inflammatory factors, IL10 terminates immune responses through its inhibitory actions on macrophages as well as lymphocytes. In addition, IL10 was also found to inhibit the production of cytokines such as IL1, TNF $\alpha$, and IL6 by LPS-activated macrophages (Fiorentino et al. 1991). These results may well interpret why the pro-inflammatory factors (IL1 $\beta$, $\mathrm{TNF} \alpha$, and IL6) were suppressed while IL10 was highly expressed in the $\mathrm{Crhr}^{-/-}$mice during the acute inflammatory responses in our study. Based on these reports, our results suggested that CRHR1 exerted the proinflammatory effects through recruitment of macrophages and therefore enhanced production of proinflammatory mediators, such as IL1 $\beta$, IL6, and TNF $\alpha$. Moreover, decreased production of anti-inflammatory factor, IL10, also contributed to CRHR1mediated proinflammatory action. What is more, $\mathrm{NF \kappa B}$ and STAT3 act in positive feedback loops to enhance the production of cytokines and chemokines that recruit additional immune cells, which maintain tumor-associated inflammation (Greten et al. 2004, Bollrath et al. 2009). Clinical studies have revealed that the activation of NFKB and STAT3 was increased in patients with UC and particularly in those who progressed to CRC (Popivanova et al. 2008, Li et al. 2010). Our results are consistent with this report about NFKB and STAT3, $C r h r 1^{+/+}$mice displayed increased NFKB and STAT3 activity accompanied with higher proinflammatory cytokines expression, which may contribute to the tumor development.

Besides its importance during early tumor promotion, CRHR1 also affected tumor formation during late stages of CAC. The $\mathrm{Crhr}^{+/+}$mice killed on day 80 exhibited less apoptotic and higher proliferative cells. On one hand, our results showed that the expression of BCL2 was decreased whereas BAX expression was increased in the colon of $\mathrm{Crhr}^{-/-}$mice. CRH was found to regulate apoptosis through BCL2 and BAX pathway in the mouse prostate cancer cell line (Jin et al. 2011). Activation of NFאB in intestinal epithelial cells enhances survival pathways that are needed for the formation of tumors (Greten et al. 2004). NFкB transactivates BCL2 expression for the suppression of apoptosis, which is mediated through a functional NFKB site identified in the BCL2 p2 promoter (Catz \& Johnson 2001). It was demonstrated that CRHR1 might be associated with the regulation of NFאB activity. CRH-deficient mice were shown to have reduced NFKB activity in thymus and spleen during inflammatory challenge by LPS (Zhao \& Karalis 2002). Also, CRH induced translocation of NFKB subunit p65 from the cytoplasm to the nucleus by binding to specific DNA sequence and enhancing $\mathrm{NF} \kappa \mathrm{B}$-driven transcription activity in the human normal epidermal keratinocytes derived from primary cultures (Zbytek et al. 2004). Together with these

Published by Bioscientifica Ltd. 
studies, our results in the CAC mouse model suggest that CRHR1 activation may stimulate NFкB-BCL2 pathway and inhibit BAX and therefore suppress apoptosis in colonic cells. On the other hand, less proliferative cells were observed and decreased STAT3 phosphorylation was detected in the colons of $C r h r 1^{-/-}$mice. As we know, STATs are latent transcription factors that mediate cytokine and growth factor-directed transcription (Darnell 1997), and active STAT3 is required for enhancing cell growth (Bromberg et al. 1999). Therefore, our data suggest that CRHR1 activation may promote STAT3 phosphorylation and therefore drastically enhance cell proliferation.

In summary, our study provides evidence for a proinflammatory and protumorigenic role of CRHR1 in the model of CAC by inducing macrophages to release proinflammatory cytokines and activating NF $\kappa$ B-BCL2 and STAT3 signals to reduce apoptosis and enhance proliferation. These results may be helpful in developing novel therapeutic approaches for dealing with devastating CAC.

\section{Declaration of interest}

The authors declare that there is no conflict of interest that could be perceived as prejudicing the impartiality of the research reported.

\section{Funding}

This work was supported by the Natural Science Foundation of China (No. 91129711), Jiangsu Provincial fund (No.10KJA350031), and by the Priority Academic Program Development of Jiangsu Higher Education Institutions.

\section{Author contribution statement}

The authors have made the following declarations about their contributions: $Y$ Liu contributed to study concept and design, analysis and interpretation of data, drafting of the manuscript, and statistical analysis; X Fang, J Yuan, Z Sun, and R Wan contributed to the acquisition of data; C Li, L Li, and C Zhu contributed to important technical and intellectual content of the study; R Li contributed to important technical and intellectual content of the study and provided material support; R Guo and L Jin contributed to the study concept and design; and S Li contributed to the study concept and design, critical revision, obtaining funding and supervised the study.

\section{Acknowledgements}

The authors thank Mr Changle Zhu and Shulong Shen in the Department of pathology in Jiangsu Province Hospital of TCM for their technical assistance in histopathological analysis.

\section{References}

Audhya T, Jain R \& Hollander CS 1991 Receptor-mediated immunomodulation by corticotropin-releasing factor. Cellular Immunology 134 77-84. (doi:10.1016/0008-8749(91)90332-6)
Balkwill F \& Mantovani A 2001 Inflammation and cancer: back to Virchow? Lancet 357 539-545. (doi:10.1016/S0140-6736(00)04046-0)

Bateman A, Singh A, Kral T \& Solomon S 1989 The immune-hypothalamicpituitary-adrenal axis. Endocrine Reviews 10 92-112. (doi:10.1210/edrv10-1-92)

Bollrath J, Phesse TJ, von Burstin VA, Putoczki T, Bennecke M, Bateman T, Nebelsiek T, Lundgren-May T, Canli O, Schwitalla S et al. 2009 gp130-mediated Stat3 activation in enterocytes regulates cell survival and cell-cycle progression during colitis-associated tumorigenesis. Cancer Cell 15 91-102. (doi:10.1016/j.ccr.2009.01.002)

Bromberg JF, Wrzeszczynska MH, Devgan G, Zhao Y, Pestell RG, Albanese C \& Darnell JE Jr 1999 Stat3 as an oncogene. Cell 98 295-303. (doi:10.1016/S0092-8674(00)81959-5)

Catz SD \& Johnson JL 2001 Transcriptional regulation of bcl-2 by nuclear factor $\kappa \mathrm{B}$ and its significance in prostate cancer. Oncogene $\mathbf{2 0}$ 7342-7351. (doi:10.1038/sj.onc.1204926)

Darnell JE Jr 1997 STATs and gene regulation. Science 277 1630-1635. (doi:10.1126/science.277.5332.1630)

Eaden JA, Abrams KR \& Mayberry JF 2001 The risk of colorectal cancer in ulcerative colitis: a meta-analysis. Gut 48 526-535. (doi:10.1136/gut. 48.4.526)

Elenkov IJ \& Chrousos GP 1999 Stress hormones, Th1/Th2 patterns, pro/anti-inflammatory cytokines and susceptibility to disease. Trends in Endocrinology and Metabolism 10 359-368. (doi:10.1016/S10432760(99)00188-5)

Fiorentino DF, Zlotnik A, Mosmann TR, Howard M \& O'Garra A 1991 IL-10 inhibits cytokine production by activated macrophages. Journal of Immunology 147 3815-3822.

Greten FR, Eckmann L, Greten TF, Park JM, Li ZW, Egan LJ, Kagnoff MF \& Karin M 2004 IKK $\beta$ links inflammation and tumorigenesis in a mouse model of colitis-associated cancer. Cell 118 285-296. (doi:10.1016/j. cell.2004.07.013)

Grivennikov S, Karin E, Terzic J, Mucida D, Yu GY, Vallabhapurapu S, Scheller J, Rose-John S, Cheroutre H, Eckmann L et al. 2009 IL-6 and Stat 3 are required for survival of intestinal epithelial cells and development of colitis-associated cancer. Cancer Cell 15 103-113. (doi:10.1016/j.ccr.2009.01.001)

Grivennikov SI, Greten FR \& Karin M 2010 Immunity, inflammation, and cancer. Cell 140 883-899. (doi:10.1016/j.cell.2010.01.025)

Gross A, McDonnell JM \& Korsmeyer SJ 1999 BCL-2 family members and the mitochondria in apoptosis. Genes and Development 13 1899-1911. (doi:10.1101/gad.13.15.1899)

Im E, Rhee SH, Park YS, Fiocchi C, Tache Y \& Pothoulakis C 2010 Corticotropin-releasing hormone family of peptides regulates intestinal angiogenesis. Gastroenterology 138 2457-2467, 2467.e2451-2455. (doi:10.1053/j.gastro.2010.02.055)

Jin L, Zhang Q, Guo R, Wang L, Wang J, Wan R, Zhang R, Xu Y \& Li S 2011 Different effects of corticotropin-releasing factor and urocortin 2 on apoptosis of prostate cancer cells in vitro. Journal of Molecular Endocrinology 47 219-227. (doi:10.1530/JME-11-0048)

Karin M, Lawrence T \& Nizet V 2006 Innate immunity gone awry: linking microbial infections to chronic inflammation and cancer. Cell $\mathbf{1 2 4}$ 823-835. (doi:10.1016/j.cell.2006.02.016)

Kawahito Y, Sano H, Mukai S, Asai K, Kimura S, Yamamura Y, Kato H, Chrousos GP, Wilder RL \& Kondo M 1995 Corticotropin releasing hormone in colonic mucosa in patients with ulcerative colitis. Gut $\mathbf{3 7}$ 544-551. (doi:10.1136/gut.37.4.544)

Kohno M, Kawahito Y, Tsubouchi Y, Hashiramoto A, Yamada R, Inoue KI, Kusaka Y, Kubo T, Elenkov IJ, Chrousos GP et al. 2001 Urocortin expression in synovium of patients with rheumatoid arthritis and osteoarthritis: relation to inflammatory activity. Journal of Clinical Endocrinology and Metabolism 86 4344-4352. (doi:10.1210/ jcem.86.9.7827)

Li Y, de Haar C, Chen M, Deuring J, Gerrits MM, Smits R, Xia B, Kuipers EJ \& van der Woude CJ 2010 Disease-related expression of the IL6/STAT3/ SOCS3 signalling pathway in ulcerative colitis and ulcerative 
colitis-related carcinogenesis. Gut 59 227-235. (doi:10.1136/gut.2009. 184176)

Lin WW \& Karin M 2007 A cytokine-mediated link between innate immunity, inflammation, and cancer. Journal of Clinical Investigation 117 1175-1183. (doi:10.1172/JCI31537)

Oltvai ZN, Milliman CL \& Korsmeyer SJ 1993 Bcl-2 heterodimerizes in vivo with a conserved homolog, Bax, that accelerates programmed cell death. Cell 74 609-619. (doi:10.1016/0092-8674(93)90509-O)

Pickert G, Neufert C, Leppkes M, Zheng Y, Wittkopf N, Warntjen M, Lehr HA, Hirth S, Weigmann B, Wirtz S et al. 2009 STAT3 links IL-22 signaling in intestinal epithelial cells to mucosal wound healing. Journal of Experimental Medicine 206 1465-1472. (doi:10.1084/jem. 20082683)

Popivanova BK, Kitamura K, Wu Y, Kondo T, Kagaya T, Kaneko S, Oshima M, Fujii C \& Mukaida N 2008 Blocking TNF- $\alpha$ in mice reduces colorectal carcinogenesis associated with chronic colitis. Journal of Clinical Investigation 118 560-570.

Qian BZ \& Pollard JW 2010 Macrophage diversity enhances tumor progression and metastasis. Cell 141 39-51. (doi:10.1016/j.cell.2010. 03.014)

Radulovic M, Dautzenberg FM, Sydow S, Radulovic J \& Spiess J 1999 Corticotropin-releasing factor receptor 1 in mouse spleen: expression after immune stimulation and identification of receptor-bearing cells. Journal of Immunology 162 3013-3021.

Rankin JA 2004 Biological mediators of acute inflammation. AACN Clinical Issues 15 3-17. (doi:10.1097/00044067-200401000-00002)

Reed JC 1994 Bcl-2 and the regulation of programmed cell death. Journal of Cell Biology 124 1-6. (doi:10.1083/jcb.124.1.1)

Reed JC 1996 Mechanisms of Bcl-2 family protein function and dysfunction in health and disease. Behring Institute Mitteilungen 1996 72-100.

Saruta M, Takahashi K, Suzuki T, Torii A, Kawakami M \& Sasano H 2004 Urocortin 1 in colonic mucosa in patients with ulcerative colitis. Journal of Clinical Endocrinology and Metabolism 89 5352-5361. (doi:10.1210/jc.2004-0195)

Scopa CD, Mastorakos G, Friedman TC, Melachrinou M, Merino MJ \& Chrousos GP 1994 Presence of immunoreactive corticotropin releasing hormone in thyroid lesions. American Journal of Pathology 145 $1159-1167$.

Shacter E \& Weitzman SA 2002 Chronic inflammation and cancer. Oncology 16 217-226, 229 discussion 230-232.

van Tol EA, Petrusz P, Lund PK, Yamauchi M \& Sartor RB 1996 Local production of corticotropin releasing hormone is increased in experimental intestinal inflammation in rats. Gut 39 385-392. (doi:10.1136/gut.39.3.385)

Tsatsanis C, Androulidaki A, Dermitzaki E, Gravanis A \& Margioris AN 2007 Corticotropin releasing factor receptor 1 (CRF1) and CRF2 agonists exert an anti-inflammatory effect during the early phase of inflammation suppressing LPS-induced TNF- $\alpha$ release from macrophages via induction of COX-2 and PGE2. Journal of Cellular Physiology $\mathbf{2 1 0}$ 774-783. (doi:10.1002/jсp.20900)

Van Pett K, Viau V, Bittencourt JC, Chan RK, Li HY, Arias C, Prins GS, Perrin M, Vale W \& Sawchenko PE 2000 Distribution of mRNAs encoding CRF receptors in brain and pituitary of rat and mouse. Journal of Comparative
Neurology 428 191-212. (doi:10.1002/1096-9861(20001211)428:2 $<191:: A I D-C N E 1>3.0 . C O ; 2-U)$

Vaughan J, Donaldson C, Bittencourt J, Perrin MH, Lewis K, Sutton S, Chan R, Turnbull AV, Lovejoy D, Rivier C et al. 1995 Urocortin, a mammalian neuropeptide related to fish urotensin I and to corticotropin-releasing factor. Nature 378 287-292. (doi:10.1038/378287a0)

Wan R, Guo R, Chen C, Jin L, Zhu C, Zhang Q, Xu Y \& Li S 2013 Urocortin increased LPS-induced endothelial permeability by regulating the cadherin-catenin complex via corticotrophin-releasing hormone receptor 2. Journal of Cellular Physiology 228 1295-1303. (doi:10.1002/ jcp.24286)

Webster EL, Torpy DJ, Elenkov IJ \& Chrousos GP 1998 Corticotropinreleasing hormone and inflammation. Annals of the New York Academy of Sciences 840 21-32. (doi:10.1111/j.1749-6632.1998.tb09545.x)

Wu Y, Xu Y, Zhou H, Tao J \& Li S 2006 Expression of urocortin in rat lung and its effect on pulmonary vascular permeability. Journal of Endocrinology 189 167-178. (doi:10.1677/joe.1.06607)

Wu Y, Hu J, Zhang R, Zhou C, Xu Y, Guan X \& Li S 2008 Enhanced intracellular calcium induced by urocortin is involved in degranulation of rat lung mast cells. Cellular Physiology and Biochemistry 21 173-182. (doi:10.1159/000113759)

Xu Y, Zhang R, Chen J, Zhang Q, Wang J, Hu J, Guan X, Jin L, Fu H, Gui B et al. 2009 Urocortin promotes the development of vasculitis in a rat model of thromboangiitis obliterans via corticotrophin-releasing factor type 1 receptors. British Journal of Pharmacology 157 1368-1379. (doi:10.1111/j.1476-5381.2009.00210.x)

Yuan PQ, Wu SV, Elliott J, Anton PA, Chatzaki E, Million M \& Tache Y 2012 Expression of corticotropin releasing factor receptor type 1 (CRF1) in the human gastrointestinal tract and upregulation in the colonic mucosa in patients with ulcerative colitis. Peptides 38 62-69. (doi:10.1016/j.peptides.2012.07.028)

Zaki MH, Boyd KL, Vogel P, Kastan MB, Lamkanfi M \& Kanneganti TD 2010 The NLRP3 inflammasome protects against loss of epithelial integrity and mortality during experimental colitis. Immunity 32 379-391. (doi:10.1016/j.immuni.2010.03.003)

Zaki MH, Vogel P, Malireddi RK, Body-Malapel M, Anand PK, Bertin J, Green DR, Lamkanfi M \& Kanneganti TD 2011 The NOD-like receptor NLRP12 attenuates colon inflammation and tumorigenesis. Cancer Cell 20 649-660. (doi:10.1016/j.ccr.2011.10.022)

Zbytek B, Pfeffer LM \& Slominski AT 2004 Corticotropin-releasing hormone stimulates NF- $\kappa$ B in human epidermal keratinocytes. Journal of Endocrinology 181 R1-R7. (doi:10.1677/joe.0.181R001)

Zhao J \& Karalis KP 2002 Regulation of nuclear factor- $\kappa$ B by corticotropinreleasing hormone in mouse thymocytes. Molecular Endocrinology 16 2561-2570. (doi:10.1210/me.2001-0334)

Zhu H, Wang J, Li J \& Li S 2011 Corticotropin-releasing factor family and its receptors: pro-inflammatory or anti-inflammatory targets in the periphery? Inflammation Research 60 715-721. (doi:10.1007/s00011011-0329-2)

Zocco D, McMorrow JP \& Murphy EP 2010 Histamine modulation of peripheral CRH receptor type $1 \alpha$ expression is dependent on $\mathrm{Ca}(2+)$ signalling and NF- $\kappa \mathrm{B} / \mathrm{p} 65$ transcriptional activity. Molecular Immunology 47 1426-1437. (doi:10.1016/j.molimm.2010.02.012)

Received in final form 6 June 2014

Accepted 10 June 2014 http://erc.endocrinology-journals.org DOI: 10.1530/ERC-14-0239
(C) 2014 Society for Endocrinology Printed in Great Britain
Published by Bioscientifica Ltd. 